\title{
Determinación de Constantes Cinéticas de Abatimiento Bacteriano en Lagunas de Estabilización Facultativas de la Provincia de Mendoza y Modelo de Correlación de Temperatura Aire - Agua
}

\author{
Determination of kinetic constants of bacterial \\ abatement in facultative stabilization lagoons \\ of the province of Mendoza and air - water \\ temperature correlation model
}

\section{José Flores}

Grupo de Estudio de Impacto Ambiental - Departamento de Ingeniería Civil. Facultad Regional Mendoza - Universidad Tecnológica Nacional - Argentina. Grupo de Ingeniería Sanitaria del Instituto de Hidráulica Facultad de Ingeniería - Universidad Nacional de Cuyo - Argentina. josealbertoflores1702@gmail.com

\section{Emilio Gastón Paez Villavisencio}

Grupo de estudio de impacto ambiental - Departamento de Ingeniería Civil Facultad Regional Mendoza - Universidad Tecnológica Nacional - Argentina. gastonpaez7@gmail.com.

\section{Resumen}

Las lagunas de estabilización facultativas son uno de los sistemas más económicos y eficientes de tratamiento biológico de líquidos residuales, por los bajos costos de operación, mantenimiento, y la eficiencia en el abatimiento de bacterias patógenas y de huevos parasitarios.

La calidad del efluente está determinada por condiciones naturales que es necesario predecir y cuantificar eficientemente. 
Esta investigación tiene como objetivos determinar las constantes cinéticas de abatimiento de bacterias indicadoras de contaminación fecal como medida indirecta de la presencia de bacterias patógenas y obtener un modelo de correlación de temperaturas aire - líquido que permitirá estimar las temperaturas del efluente en la laguna y así predecir la eficiencia de remoción de carga bacteriológica y orgánica del sistema de tratamiento para las condiciones regionales.

Esta investigación tiene como objetivo contribuir a la formulación analítica del tratamiento de efluentes por lagunas de estabilización y optimizar su cálculo.

Palabras clave: Lagunas, Efluente, Abatimiento, Correlación, Cinéticas

\begin{abstract}
Stabilization Lagoons are one of the most economical and efficient systems of biological treatment of residual liquids, by the low energy and maintenance costs, joined to the simple operation and high efficiency in the abatement of pathogenic bacteria and parasitic eggs.

The quality of the effluent is determined by natural conditions that need to be predicted and quantified efficiently.

The purpose of this research is to determine the kinetic constants of fecal contamination indicator bacteria as an indirect measure of the presence of pathogenic bacteria and to obtain a correlation model of air - liquid temperatures that will allow estimating the effluent temperatures in the lagoon and thus predict the efficiency of bacteriological and organic load removal from the treatment system for regional conditions.

This research aims to contribute to the analytical formulation of effluent treatment by stabilization Lagoons and optimize its calculation.
\end{abstract}

Keywords: Lagoons, Effluent, Abatement, Correlation, Kinetics

\title{
INTRODUCCIÓN
}

El término lagunas de estabilización describe a estanques construidos de tierra, de profundidad reducida $(<5 \mathrm{~m}$.), diseñados para el tratamiento de aguas residuales, por medio de la interacción de la biomasa (algas, bacterias, protozoarios, etc.), la materia orgánica del desecho y otros procesos naturales (factores físicos, químicos y meteorológicos).

Se llaman facultativas porque predominantemente actúan bacterias denominadas FACULTATIVAS que tienen la particularidad de poder desarrollar sus actividades metabólicas tanto en presencia como en ausencia de oxigeno molecular disuelto en agua. Este tipo de laguna basa su funcionamiento en relaciones simbióticas entre las bacterias y las algas del sistema.

La materia orgánica es utilizada por los microorganismos en sus reacciones metabólicas como fuente de carbono y energía para la producción de biomasa. Estas reacciones liberan compuestos inorgánicos solubles y dióxido de carbono.

El dióxido de carbono es utilizado por las algas en el proceso de la fotosíntesis, liberando oxígeno molecular en solución. 
En cuanto al abatimiento de organismos patógenos, se destaca la remoción de parásitos que ocurre principalmente por sedimentación y la eliminación de bacterias por un proceso denominado mortalidad, abatimiento o decaimiento bacteriano.

Existen variados postulados que explican esta mortalidad bacteriana.

Entre los factores principales se señalan:

- $\quad$ Sedimentación.

- Antagonismo con otros organismos (protozoos).

- Temperatura.

- Radiación solar.

- Variaciones de $\mathrm{pH}$.

\section{METODOS DE DISEÑO}

El proyecto de estas lagunas se efectúa siguiendo una metodología racional, en cuyo caso la herramienta de diseño más ampliamente aceptada ha sido la aplicación del modelo de flujo disperso. El modelo de flujo disperso, también conocido como ecuación de transporte unidimensional, es el modelo hidráulico real a aplicar y que permite obtener valores mucho más exactos respecto del submodelo de mezcla completa que es ideal. Constituye un modelo general para el transporte de cualquier soluto, ya sea reactivo o conservativo (trazador), en una infinidad de medios.

\section{Consideraciones a tener en cuenta}

Se asume que tanto la asimilación de la materia orgánica como el abatimiento de indicadores de contaminación fecal se ajustan más a una reacción de primer orden.

Todos los parámetros de diseño de las lagunas tienen una dependencia directa con la temperatura del líquido.

\section{Importancia de esta investigación}

En nuestro país no se han efectuado suficientes investigaciones en lagunas de estabilización para obtener las constantes cinéticas de abatimiento de indicadores de contaminación fecal como medida indirecta de la presencia de bacterias patógenas y de la correlación entre la temperatura del aire y la temperatura del agua de las lagunas.

Su determinación para el diseño de futuras lagunas por el modelo de flujo disperso es de fundamental importancia.

\section{ASPECTOS BÁSICOS}

\section{Clasificación de lagunas y nomenclatura}

De acuerdo con el lugar que ocupan en la serie, las lagunas pueden clasificarse como primarias, secundarias, terciarias, etc. De acuerdo con la secuencia de las unidades, pueden clasificarse en lagunas en serie o en paralelo, pudiendo encontrarse combinaciones de varios tipos.

El número de unidades en serie tiene relación primordial con la topografía y superficie del terreno y con el nivel de calidad requerido en el efluente del sistema. 


\section{CRITERIOS DE CALIDAD}

Para el caso de reuso de aguas residuales para la agricultura, no existe cuerpo receptor y los criterios de calidad han sido establecidos por la OMS “Organización Mundial de la Salud”, estableciéndose tres categorías de reuso con recomendaciones específicas en la siguiente forma:

\section{Categoría A}

Corresponde a riego de cultivos cuya producción comúnmente se consume cruda, campos deportivos y parques públicos. El grupo expuesto está compuesto por trabajadores, consumidores y el público. Para este caso se recomienda un tratamiento por un sistema de lagunas de estabilización o tratamiento equivalente, que permita lograr la siguiente calidad microbiológica:

- $\quad$ Nematodos intestinales: menor o igual a 1 huevo por litro.

- Coliformes fecales: menor o igual a 1000 NMP/100 ml (NMP "Número mas probable)

\section{Categoría B}

Corresponde a riego de cultivos de cereales industriales y forrajeros, praderas y árboles. El grupo expuesto lo constituyen los trabajadores y para este caso se recomienda un tratamiento por lagunas de estabilización con un período de retención de 8 a 10 días o eliminación equivalente de nematodos intestinales. En este caso no se recomienda norma alguna para coliformes fecales, estableciéndose únicamente un nivel menor o igual a 1 huevo por litro para los nematodos intestinales.

\section{Categoría C}

Corresponde a riego localizado de los cultivos de la Categoría B, cuando ni los trabajadores ni el público están expuestos. En este caso no son aplicables limitaciones en las concentraciones de nematodos intestinales y coliformes fecales y el tratamiento previo es dependiente de las exigencias de la tecnología de riego, requiriéndose por lo menos sedimentación primaria.

\section{DISEÑO DE REACTORES}

\section{Reactor con flujo disperso}

Este modelo considera un reactor con flujo laminar tipo pistón, en el cual el mecanismo de transporte de un contaminante está afectado por la dispersión convectiva en la dirección del flujo y en el otro sentido por la difusión molecular axial. (Poujol A., 2018)

\section{Comportamiento de la temperatura}

El conocimiento de este parámetro es de gran significado para el diseño de lagunas de estabilización, ya que los procesos de asimilación de la materia orgánica y de reducción bacterianas son dependientes de la temperatura y un incremento de la temperatura del líquido sobre la del ambiente, puede producir una reducción apreciable en requisitos de área para las lagunas.

Estas correlaciones han sido desarrolladas a partir de mediciones de temperaturas del líquido y ambiente, en instalaciones existentes. Por consiguiente, su uso está limitado a condiciones climáticas similares. 
En la segunda parte de la presente investigación se desarrolla un modelo regional de correlación de temperatura Aire - Agua.

\section{DESCRIPCION DEL SISTEMA DE LAGUNAS DE ESTABILIZACION DONDE SE EFECTUO LA INVESTIGACION}

El sistema de lagunas de estabilización de Campo Espejo se halla ubicado en el departamento Las Heras de la provincia de Mendoza, y es la Planta Depuradora donde se efectuó la investigación.

Las lagunas se ubican a una altitud de $694 \mathrm{~m}$ sobre el nivel del mar, a una latitud de $32^{\circ} 47^{\prime}$ y una longitud de $68^{\circ} 48^{\prime}$ medidos en la esquina suroeste de la propiedad.

Consta de 36 lagunas distribuidas en 12 series de 3 lagunas rectangulares cada una, primarias, secundarias y terciarias de dimensiones variables, con anchos que van desde los 90 $\mathrm{m}$ hasta los $155 \mathrm{~m}$ y largos desde los $275 \mathrm{~m}$ hasta los $950 \mathrm{~m}$.

La superficie total del sistema de 36 lagunas es de aproximadamente 300 ha., siendo la profundidad promedio de todas las lagunas de $2 \mathrm{~m}$.

Las pruebas y ensayos de la presente investigación se realizaron en la serie 3 del sistema.

La planta depuradora trata los efluentes residuales de Mendoza capital, Las Heras y parte de Godoy Cruz.
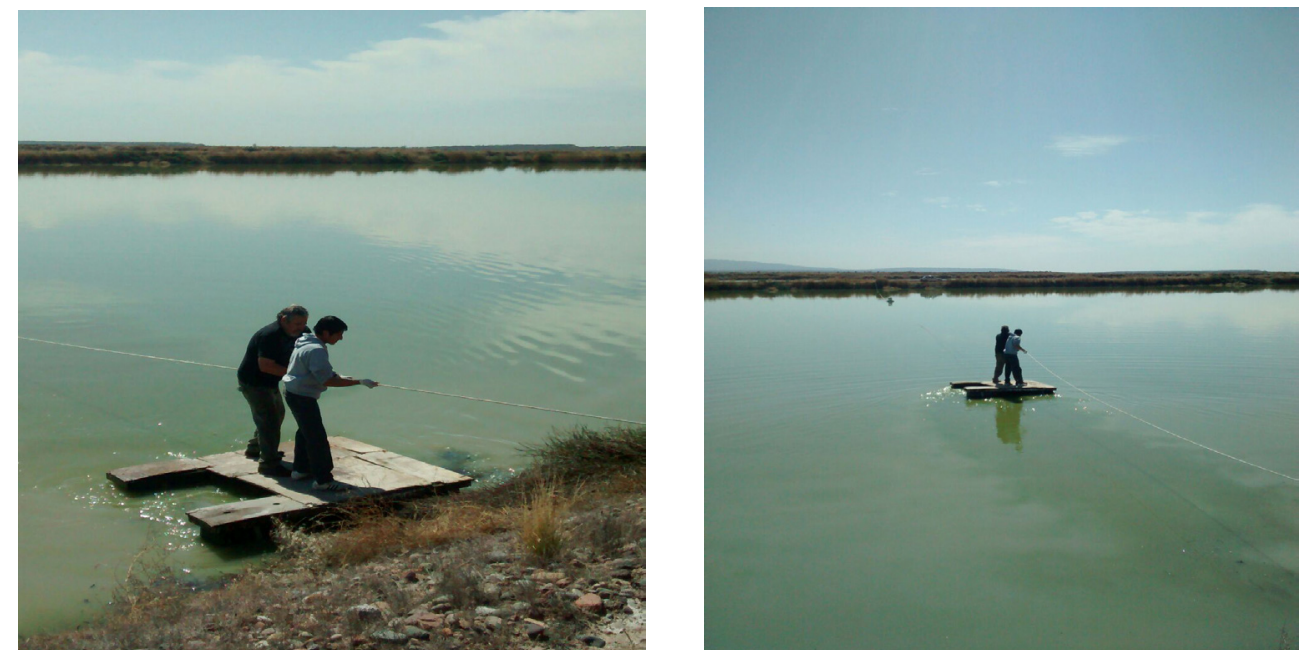

Figura 1: Traslado hacia el gabinete para extracción de datos 

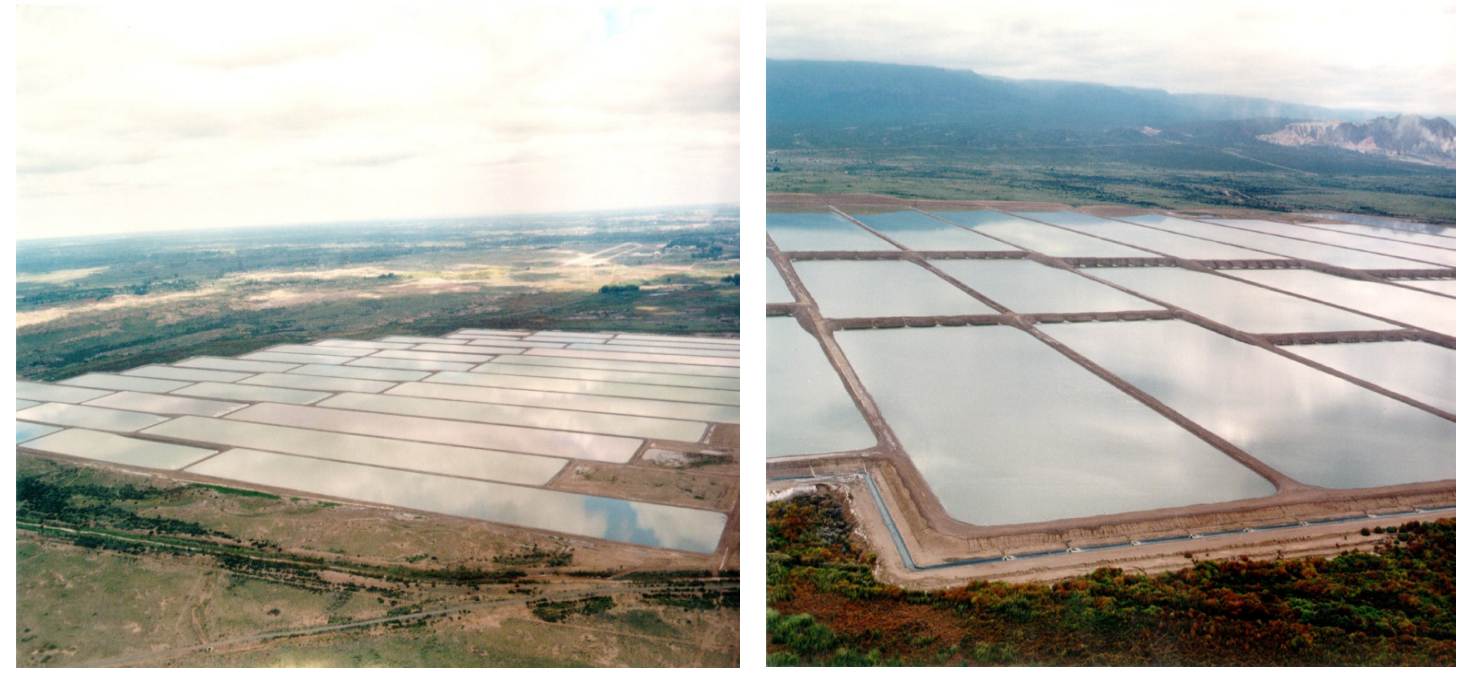

Figura 2: Lagunas de estabilización de Campo Espejo (Las Heras)

\section{ORGANISMOS INDICADORES}

El uso de las pruebas de detección de organismos coliformes como indicadores de la calidad bacteriológica del agua, se basa en información recopilada en los últimos años, principalmente en estudios sobre contaminación del agua (Yáñez F. , 1983).

Los requisitos de un indicador ideal de contaminación bacterial son (Yáñez F. , 1983):

- un componente normal de la flora intestinal de gente saludable.

- $\quad$ su hábitat debe ser exclusivamente intestinal, de modo que cuando se le detecte en el ambiente, implique contaminación fecal.

- debe estar presente cuando se detecten patógenos de origen fecal.

- debe ser incapaz de multiplicarse fuera del intestino y deben tener una tasa de mor talidad menor que la de los patógenos fecales.

- $\quad$ debe ser de fácil identificación y conteo.

- $\quad$ debe ser no patógeno.

Si bien actualmente se tiende a utilizar el indicador escherichia coli, se trabajó con el indicador coliforme fecal por que figura en la mayoría de la normativa actual.

\section{Modelo de flujo disperso}

Según lo explicado anteriormente, los dos componentes esenciales de este modelo son: la constante de mortalidad neta y la caracterización del submodelo hidráulico a través del factor de dispersión.

El modelo de dispersión axial es el más empleado, porque en sus límites cubre los dos anteriores.

Este modelo tiene aplicabilidad para la descripción real de la reducción de bacterias en lagunas, según la siguiente fórmula de Wehner y Wilhem (1956) (Yáñez F. , 1983) : 


$$
\frac{N}{N O}=\frac{4 a^{*} e^{\left(\frac{1}{2^{*} d}\right)}}{(1+a)^{2} * e^{\left(\frac{a}{2^{*} d}\right)}-(1-a)^{2} * e^{\left(-\frac{a}{2 * d}\right)}}
$$

Las constantes -a- y -d- están definidas por las siguientes relaciones:

$$
a=\left(1+4 * K b^{*} P R * d\right)^{1 / 2}
$$

$$
d=\frac{D}{U^{*} L}=\frac{D^{*} P R}{L^{2}}
$$

\section{Donde:}

No $=$ Concentración de coliformes fecales en el afluente en NMP/100 ml

$\mathrm{N}=$ Concentración de coliformes fecales en el efluente en NMP/100 ml

$\mathrm{PR}=$ Período de retención nominal en días $(\mathrm{PR}=\mathrm{V} / \mathrm{Q})$

$\mathrm{d}=$ Factor de dispersión adimensional

$\mathrm{a}=$ Constante adimensional

$\mathrm{Kb}=$ Constante de mortalidad neta en 1 /días

$\mathrm{D}=$ Coeficiente de dispersión longitudinal o axial que caracteriza el grado de mezcla en

el flujo $\left(\mathrm{m}^{2} /\right.$ día $)$

$\mathrm{U}=$ Velocidad de Flujo (m/día)

$\mathrm{L}=$ Longitud de paso del fluido desde el afluente hasta el efluente (m)

Esta relación permite interpretar adecuadamente los datos de una evaluación intensiva de campo de una laguna funcionando en equilibrio continuo.

\section{METODOS DE EVALUACIÓN DE LAGUNAS}

\section{ELABORACIÓN DE LA PRIMERA PARTE DE LA INVESTIGACIÓN: DETERMINACION DE LAS CONSTANTES CINETICAS}

\section{Resumen}

El modelo de predicción de la calidad de efluente utilizado supone que la Ley de Chick - Watson (1958) rige la remoción de bacterias en lagunas de estabilización bajo flujo discontinuo. En consecuencia, la determinación de la constante de remoción bacteriana se debe realizar bajo estas condiciones. La expresión utilizada para la determinación del coeficiente $\mathrm{Kb}$ resulta ser:

$$
\begin{aligned}
K b=K b_{20} * \theta^{\left(T-20^{\circ} \mathrm{c}\right)} \quad & \text { Temp }\left({ }^{\circ} \mathrm{C}\right)=\text { Temp }\left({ }^{\circ} \mathrm{K}\right)-273,15 \\
& { }^{\circ} \mathrm{C}=\text { Grados Celsius } \\
& { }^{\circ} \mathrm{K}=\text { Grados Kelvin }
\end{aligned}
$$


Donde:

$\theta=$ Coeficiente de dependencia de temperatura

$\mathrm{Kb}=$ Constante de mortandad bacteriana a la temperatura $\mathrm{T}$

$\mathrm{Kb}_{20}=$ Constante de mortandad bacteriana a $20^{\circ} \mathrm{C}$

Una vez obtenido el valor de $\mathrm{Kb}$, podemos determinar el valor de calidad bacteriológica $(\mathrm{N})$, a través de la siguiente expresión:

$$
N=N_{o} * e^{\left(-K b^{*} t\right)}
$$

\section{Donde:}

No $=$ Calidad bacteriológica original del agua .

$\mathrm{N}$ = Calidad bacteriológica del agua después de un tiempo t.

En las lagunas reales no se tiene condiciones de flujo discontinuo sino un flujo continuo y la ley de Chick se ve modificada por el efecto de dispersión.

\section{PRUEBAS DE CAMPO EN FLUJO DISCONTINUO}

- La evaluación completa de una laguna de estabilización en condiciones operativas se debe efectuar mediante la conducción de pruebas de campo combinadas.

- Esta evaluación permite conocer la información sobre el abatimiento de organismos patógenos, así como las condiciones hidráulicas de la laguna. Todas las mediciones de parámetros se realizaron en el Laboratorio de la Planta Depuradora. Se efectuó:

- Realización de una prueba batch o de flujo discontinuo a escala reducida dentro de la laguna. Su duración fue de 10 días.

- Evaluaciones en el afluente y efluente de las lagunas de concentración de colifor mes fecales en condiciones de equilibrio continuo, midiendo además caudales y otros parámetros.

- Se realizó una prueba en la laguna de flujo discontinuo a escala reducida (in situ) para la calibración del modelo predicción de calidad de efluentes y la determinación de las constantes cinéticas $\theta$ y Kb20, constante de la ecuación de Arrhenius modificada y constante de abatimiento bacteriano a $20^{\circ} \mathrm{C}$ respectivamente.

- Se determinaron la temperatura del líquido, la concentración de coliformes fecales al ingreso (N0) y al egreso (N) de la laguna, la relación N/N0 y su logaritmo natural tanto para el mes más frío del año como para el mes más cálido.

- Con estos datos y aplicando la ley de Chick se obtuvo el valor Kbf (cte. específica neta de mortalidad bacteriana en el mes más frío), aplicando la recta de mejor ajuste por 
mínimos cuadrados.

- De igual forma se procedió a calcular la cte. específica neta de mortalidad bacteria na Kbc para el mes más cálido registrado el mismo año.

- Con los valores de Kbf y Kbc se calcula el coeficiente $\theta$ utilizando la temperatura promedio de cada prueba de equilibrio discontinuo. A partir de la obtención del va lor de $\theta$ de la calibración se calculó el valor de $\mathrm{Kb} 20$ (cte. específica a $20^{\circ} \mathrm{C}$ ).

- Posteriormente con los parámetros calculados $\theta$ y Kb20 se obtiene la expresión $\mathrm{Kb}$, que es la constante cinética de mortalidad bacteriana para cada valor de temperatura. Esta metodología fue utilizada por el CEPIS durante todos los años que realizó sus investigaciones en lagunas de estabilización.

\section{Determinación de correlación para el coeficiente Kbf}

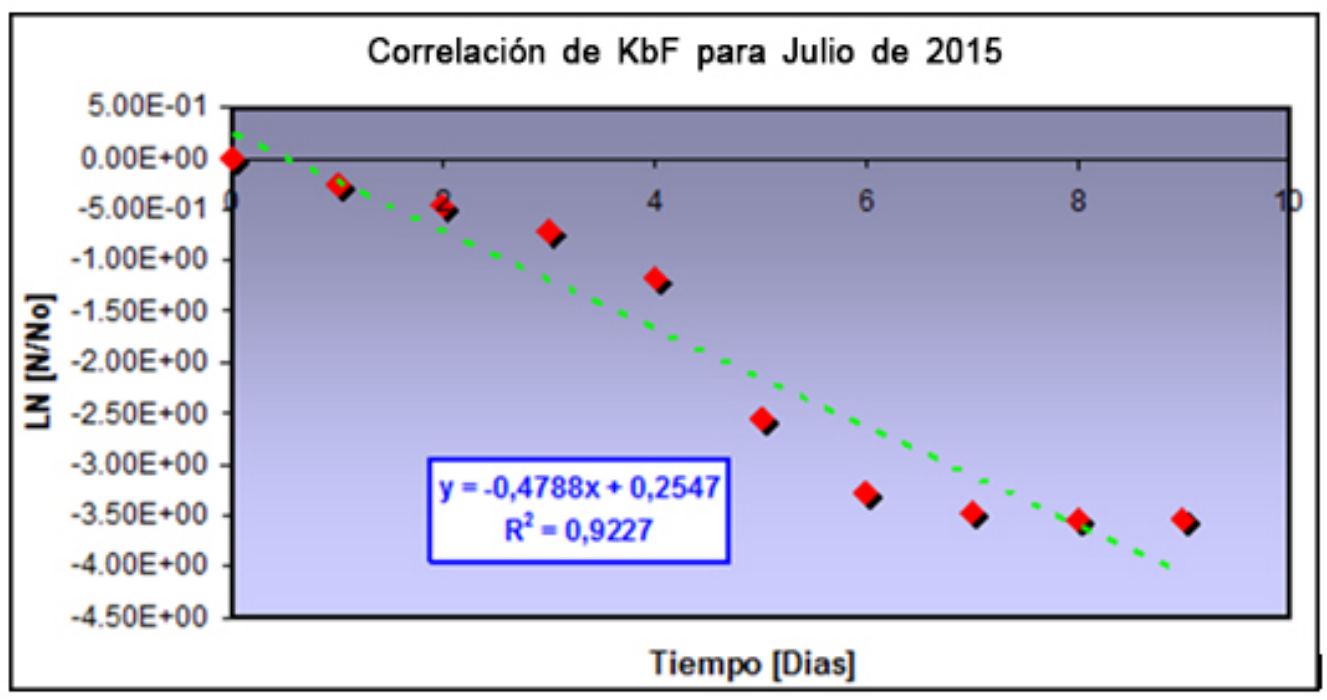

Figura 3: Gráfica de correlación del coeficiente Kbf para julio de 2015

La correlación nos otorga:

- Una ecuación de la forma $\mathrm{y}=\mathrm{a} 1^{*} \mathrm{x}+\mathrm{ao}$

- $\quad$ Coeficiente de correlación $\mathrm{R}$

Para nuestro caso los valores obtenidos fueron:

- $\quad$ ao $=0,2547$

- $\quad \mathrm{a} 1=-0,4788$

- $\quad \mathrm{Kbf}=0,4788$ (para una temperatura promedio del mes igual a $11^{\circ} \mathrm{C}$ )

- $\mathrm{R}^{2}=0,9227$ 
- $\mathrm{R}=0,9606$

Cálculo de coeficiente Kbc para el mes de mayor temperatura registrada

Determinación de correlación para el coeficiente Kbc

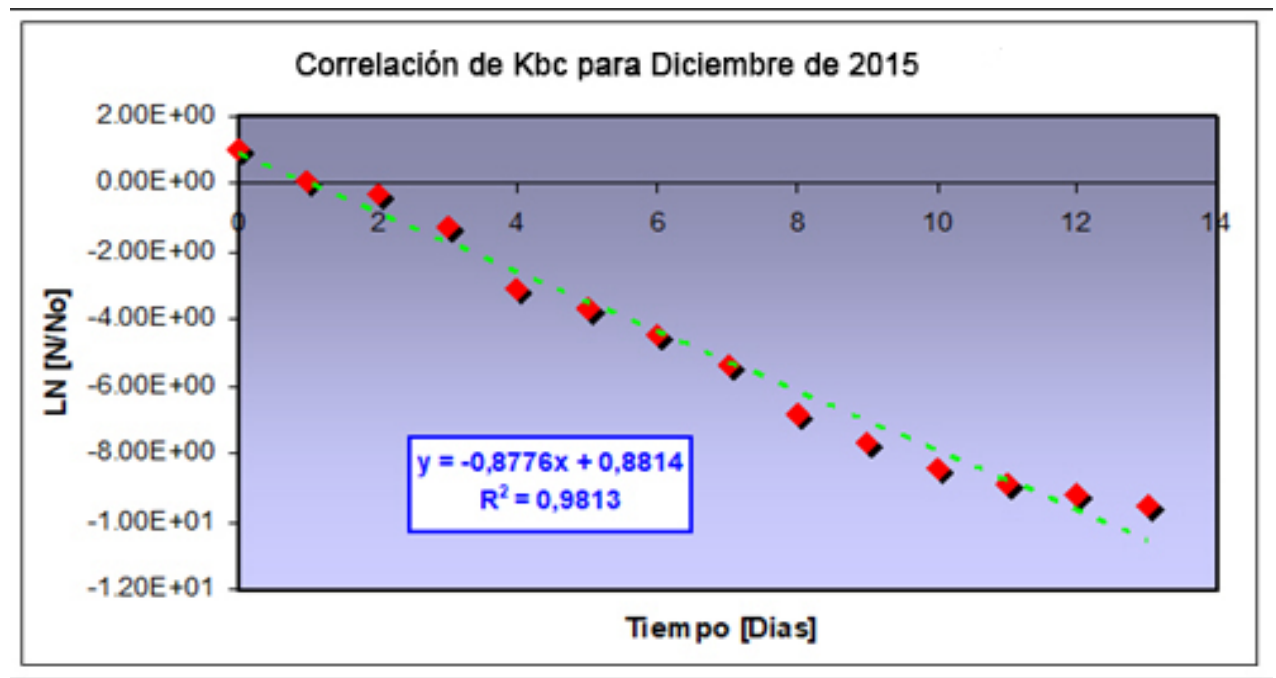

Figura 4: Gráfica de correlación del coeficiente Kbc para Diciembre de 2015

La correlación nos da:

- $\quad$ ao $=0,8814$

- $\quad \mathrm{a} 1=-0,8776$

- $\quad \mathrm{Kbc}=0,8776$ (para una temperatura promedio del mes igual a $21^{\circ} \mathrm{C}$ )

- $\mathrm{R} 2=0,9813$

- $\mathrm{R}=0,9906$

\section{Cálculo del coeficiente $\theta$}

En función de los datos obtenidos de la correlación y a partir de las siguientes expresiones calculamos el coeficiente

$$
\begin{aligned}
& K b_{C}=K b_{F} * \theta^{(T C-T F)} \\
& \theta=\left[\frac{K b_{C}}{K b_{F}}\right]^{\frac{1}{(T C-T F)}}
\end{aligned}
$$

Donde:

$\mathrm{Kbc}=$ Constante específica neta de mortalidad bacteriana para el mes más cálido 
registrado el mismo año.

$\mathrm{Kbf}=$ Constante específica neta de mortalidad bacteriana en el mes más frío.

$\mathrm{TC}=$ Temperatura del mes más cálido registrado $\left({ }^{\circ} \mathrm{C}\right)$

$\mathrm{TF}=$ Temperatura del mes más Frío registrado $\left({ }^{\circ} \mathrm{C}\right)$

Datos:

$\mathrm{Kbf}=0,4788$

$\mathrm{Kbc}=0,8776$

$\mathrm{TF}=10,80$

$\mathrm{TC}=21,11$

$K b_{C}=K b_{F} * \theta^{(T C-T F)} \Rightarrow \theta=\left[\frac{K b_{C}}{K b_{F}}\right]^{\frac{1}{(T C-T F)}}=1,060539$

Cálculo del coeficiente Kb20

$K b_{20}=K b_{F} * \theta^{\left(20^{\circ} \mathrm{C}-T F\right)}$

Donde:

$\mathrm{Kb} 20=$ Constante de mortandad bacteriana a $20^{\circ} \mathrm{C}$

$\mathrm{Kbf}=$ Constante específica neta de mortandad bacteriana en el mes más frío.

$\mathrm{TF}=$ Temperatura del mes más Frío registrado

$\theta=$ Coeficiente de dependencia de temperatura

Datos:

$\theta=1,0605$

$\mathrm{Tf}=10,8$

$\mathrm{Kbf}=0,4788$

$K b_{20}=K b_{F} * \theta^{\left(20^{\circ} \mathrm{C}-T F\right)}=0,822240$

Determinación de la ecuación del coeficiente $\mathrm{Kb}$

$$
K b=K b_{20} * \theta^{\left(T-20^{\circ} C\right)} \Rightarrow K b=0,822240 * 1,060539^{\left(T-20^{\circ} C\right)}
$$

Determinación del valor del coeficiente $\mathrm{Kb}$ para diferentes temperaturas del líquido 


\begin{tabular}{|c|c|}
\hline $\begin{array}{l}\text { Temperatura liquido } \\
{\left[{ }^{\circ} \mathrm{C}\right]}\end{array}$ & $\mathbf{K b}$ \\
\hline 1 & 0,269150 \\
\hline 2 & 0,285444 \\
\hline 3 & 0,302724 \\
\hline 4 & 0,321051 \\
\hline 5 & 0,340487 \\
\hline 6 & 0,361099 \\
\hline 7 & 0,382960 \\
\hline 8 & 0,406144 \\
\hline 9 & 0,430731 \\
\hline 10 & 0,456807 \\
\hline 11 & 0,484462 \\
\hline 12 & 0,513790 \\
\hline 13 & 0,544895 \\
\hline 14 & 0,577882 \\
\hline 15 & 0,612866 \\
\hline 16 & 0,649968 \\
\hline 17 & 0,689317 \\
\hline 18 & 0,731047 \\
\hline 19 & 0,775304 \\
\hline 20 & 0,822240 \\
\hline 21 & $\mathbf{0 , 8 7 2 0 1 7}$ \\
\hline 22 & 0,924808 \\
\hline 23 & 0,980795 \\
\hline 24 & 1,040171 \\
\hline 25 & 1,103142 \\
\hline 26 & 1,169925 \\
\hline
\end{tabular}

Tabla 1: Valor de coeficiente Kb para diferentes temperaturas de líquido

\section{MODELO DE PREDICCION DE CALIDAD DE EFLUENTE EN LAGUNAS DE ESTABILIZACION FACULTATIVAS. RESUMEN DE LA METODOLOGIA USADA.}

- Luego de calibrar los valores correspondientes de $\mathrm{Kb}$ (constante cinética de mortalidad bacteriana para cada valor de temperatura) y de las distintas temperaturas, se puede calcular la concentración de coliformes fecales en los efluentes de las lagunas aplicando la formulación de flujo disperso.

- Se trabajó en la serie 3 del sistema de lagunas. Las tablas donde se volcaron los valores calculados contienen datos de identificación de las lagunas primarias, secundarias y terciarias, sus dimensiones de largo, ancho y profundidad, calculándose el área y el 
volumen de cada una. Se tabuló el caudal promedio a tratar medido en cada laguna para los meses más fríos y más cálidos de cada año, el factor de corrección hidráulica "HCF" debido al flujo hidráulico laminar que rige las lagunas de estabilización y que hace que los tiempos de residencia hidráulica en cada laguna tiendan a ser 2/3(V/Q).

- Posteriormente se calcula la relación largo/ancho de las lagunas y los coeficientes de dispersión "d" y el parámetro adimensional "a" que tiene en cuenta la constante $\mathrm{Kb}$ de mortalidad, el coeficiente de dispersión y el tiempo de residencia hidráulico real. Luego se tabula la concentración inicial de coliformes fecales en el afluente "N0" como NMP/100 ml y el factor de características de sedimentación "SCF".

- Por último, se tabulan la concentración de coliformes en el efluente "N" tanto el calculado con el modelo calibrado como el medido en campo real, para culminar con una columna que indica la diferencia porcentual entre los valores de $\mathrm{N}$ calculados por el modelo y el efectivamente medido en campo, en el laboratorio.

\section{ELABORACIÓN DE LA SEGUNDA PARTE DE LA INVESTIGACIÓN: MODELO DE CORRELACIÓN TEMPERATURA AGUA Y AIRE.}

\section{Introducción}

El objetivo de esta parte de la investigación es determinar el modelo de correlación entre las temperaturas del aire y del agua de las lagunas de estabilización del complejo Campo Espejo tal como se indicó anteriormente, en el periodo Enero-Diciembre del 2015.

Se midieron las temperaturas del aire y del líquido, las primeras fueron proporcionadas por el servicio meteorológico de la provincia y cotejadas por una estación meteorológica adquirida para la investigación y ubicada cerca de las plantas, y para las segundas, se utilizó un circuito integrado de tres termómetros colocados a 0,74-1,20 y 2,34 metros de profundidad respectivamente, en donde tendremos en cuenta el primer y segundo sensor. Cabe aclarar que no se tiene en cuenta el sensor que se encuentra a mayor profundidad $(2,34 \mathrm{~m})$ dado que no variaba la temperatura del agua a dicha profundidad con la variación de la temperatura del aire, esto se debe a que el termómetro a tal profundidad poseía mucha inercia térmica.

Se aplicaron técnicas estadísticas descriptivas e inferenciales a las variables estudiadas. Se encontraron correlaciones para promedios mensuales, y diarios de las temperaturas del aire y del agua. Obteniéndose el mayor coeficiente de correlación para el caso de promedios mensuales $(\mathrm{r} 2=0,9749)$ cuyo valor corresponde al sensor ubicado a $0,74 \mathrm{~m}$ de la interfase (nivel de agua), cuyo modelo de regresión tiene como coeficientes $(\alpha=1,0322 ; \beta=0,469)$. Los resultados obtenidos permitirán diseñar unidades optimizadas para condiciones climáticas similares. (Saracho M. et al. , 2005) 


\section{Objetivos generales de la determinación del modelo de correlación}

- Determinar un modelo de correlación y predicción regional de temperatura del agua en función de la temperatura del líquido como variable para utilizar en métodos de diseño que tienen a la temperatura del líquido como variable. (Flores J. et al. , 2014)

- Contar con parámetros de diseño de lagunas de estabilización que hagan más eficientes los proyectos de ingeniería en la región optimizando así el costo de ejecución de plantas de tratamiento por lagunas facultativas por el uso de parámetros reales. (Flores J. et al. , 2014)

\section{Metodología seguida}

Encontrar la relación entre la temperatura del aire y la temperatura del líquido, resulta ser un factor muy importante en la velocidad de purificación del efluente.

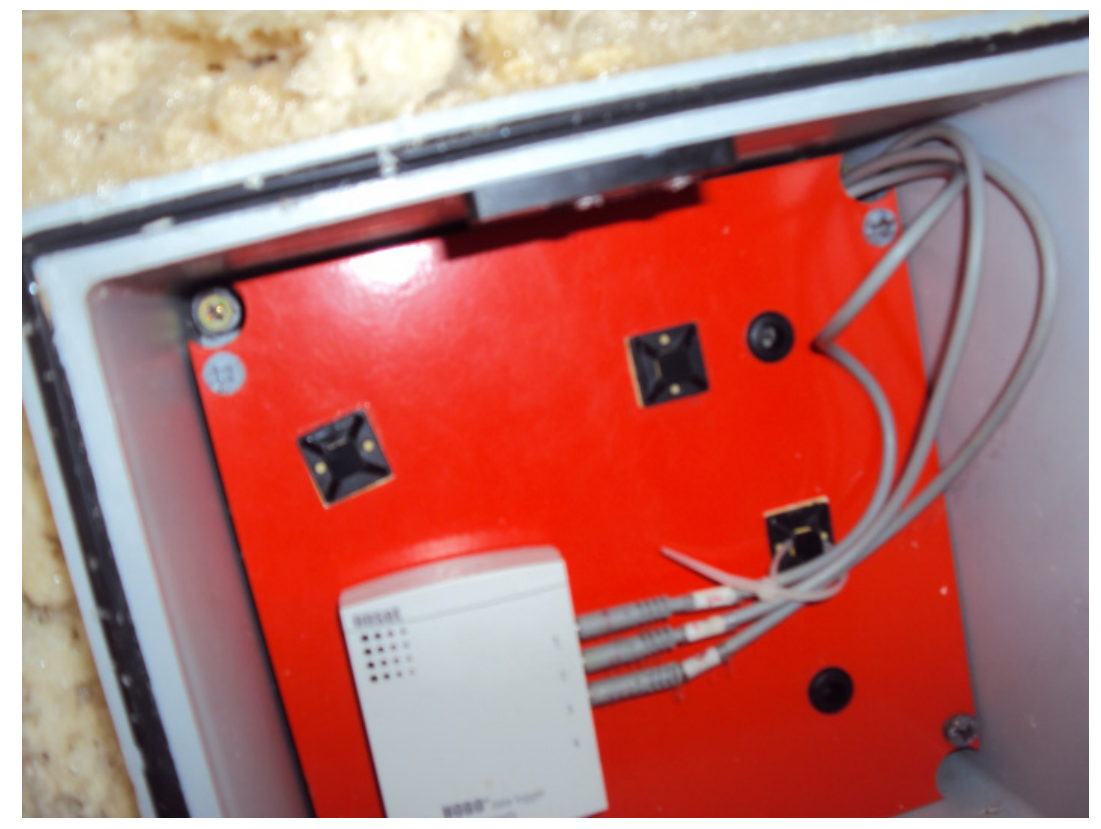

Figura 5: Sistema de Medición: Datalogger (Registrador de datos), marca Onset HOBO.

El sistema de medición de temperatura fue llevado a cabo por un datalogger, configurado para la toma de datos cada 15 minutos. Estos valores fueron promediados de manera diaria para simplificar los datos y facilitar el estudio de los mismos.

Se aplicaron técnicas estadísticas descriptivas a las variables en estudio. Para encontrar el coeficiente de correlación se trabajó con los promedios mensuales y diarios de las temperaturas del aire y del agua. En función del diseño, los módulos del sistema en estudio trabajan bajo condiciones hidráulicas similares y sometidos a iguales factores climáticos. 


\section{RESULTADOS Y DISCUSIÓN:}

\section{Metodología de toma de datos.}

- Se determinan los parámetros meteorológicos y las temperaturas en la laguna del establecimiento, en forma simultánea. (Flores J. et al. , 2014)

- Los instrumentos utilizados para este proyecto, estación meteorológica y sensores de temperatura, han sido contrastados y certificados en el IRESE, laboratorio dependiente de la Facultad Regional Mendoza de la Universidad Tecnológica Nacional. (Flores J. et al. , 2014)

\section{Temperatura del aire: Instrumental}

- Se adquirió una estación meteorológica marca Lacrosse modelo WS-2812U-IT Profesional. La misma se instaló dentro de un gabinete metálico con tela romboidal para protegerla de agentes climáticos como granizo en un sitio sin obstáculos o interferencias que pudieran modificar o afectar los parámetros medidos. Los datos obtenidos se comparan con los del Servicio Meteorológico Nacional. (Flores J. et al. , 2014)

- El equipo está vinculado en forma inalámbrica a una central con pantalla que colecta la información recogida. Desde la central, también en forma inalámbrica, la información registrada se descarga periódicamente a una computadora donde es compaginada y procesada. (Flores J. et al. , 2014)
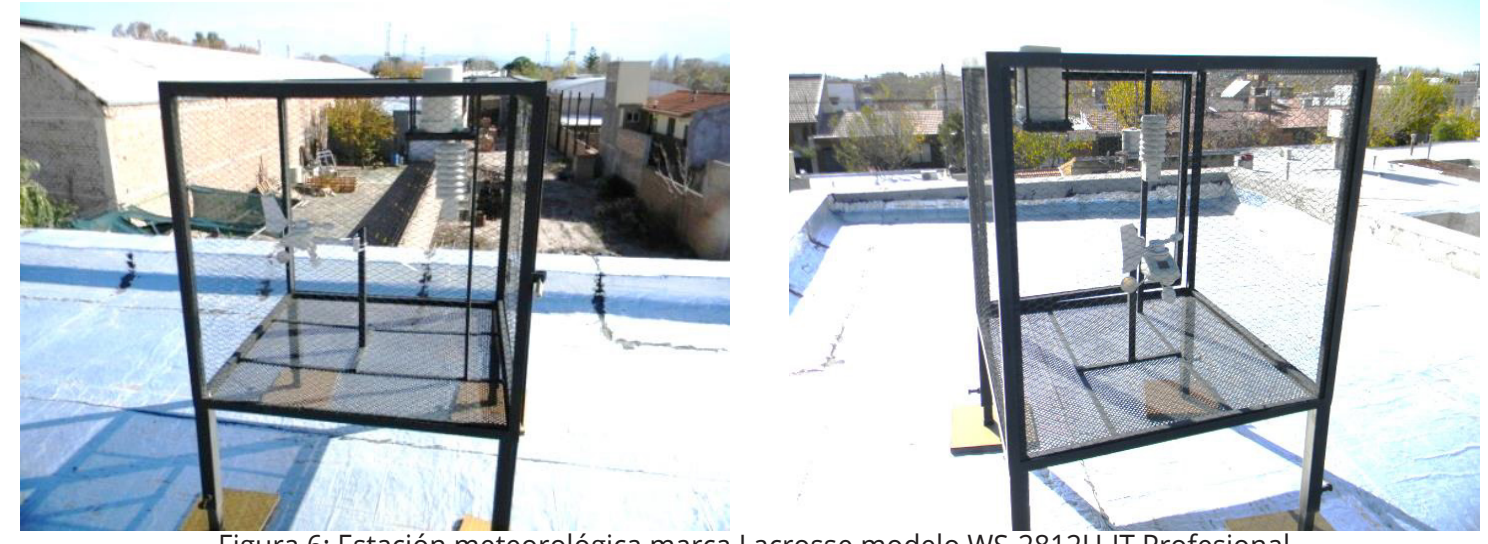

Figura 6: Estación meteorológica marca Lacrosse modelo WS-2812U-IT Profesional

\section{Temperatura del agua: Instrumental}

Para el proyecto de investigación se adquirieron tres sensores de temperatura modelo TMC20-HD junto con un data-logger para captura de datos, todos ellos montados y conectados en su estructura y gabinete. Los sensores fueron instalados en soportes con cañerías estancas y la unidad de almacenamiento en un gabinete estanco clase IP-67. 
Se proveyó un software específico para la programación de los sensores y el registro de datos y su procesamiento, para su posterior exportación a Excel. (Flores J. et al. , 2014)

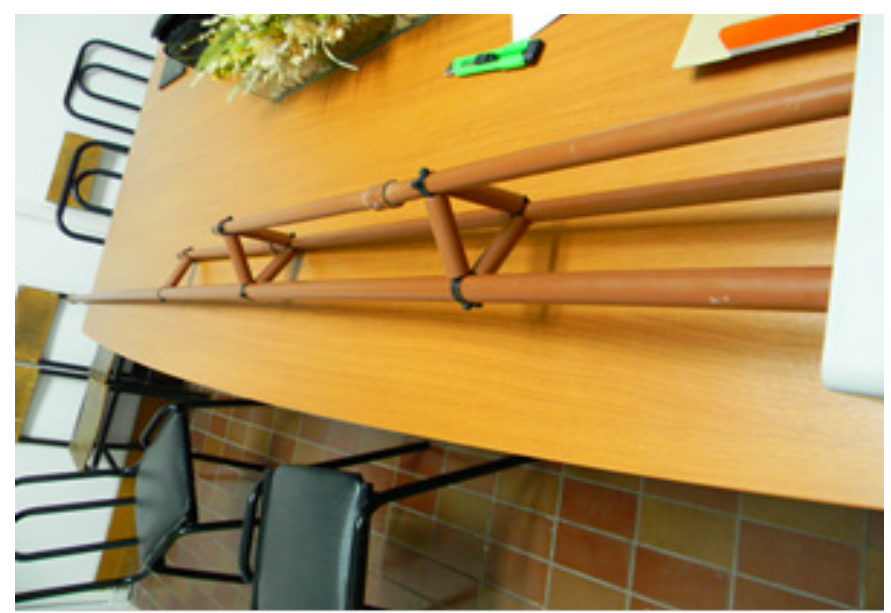

Figura 7: Soportes con cañerías estancas para instalación de sensores.

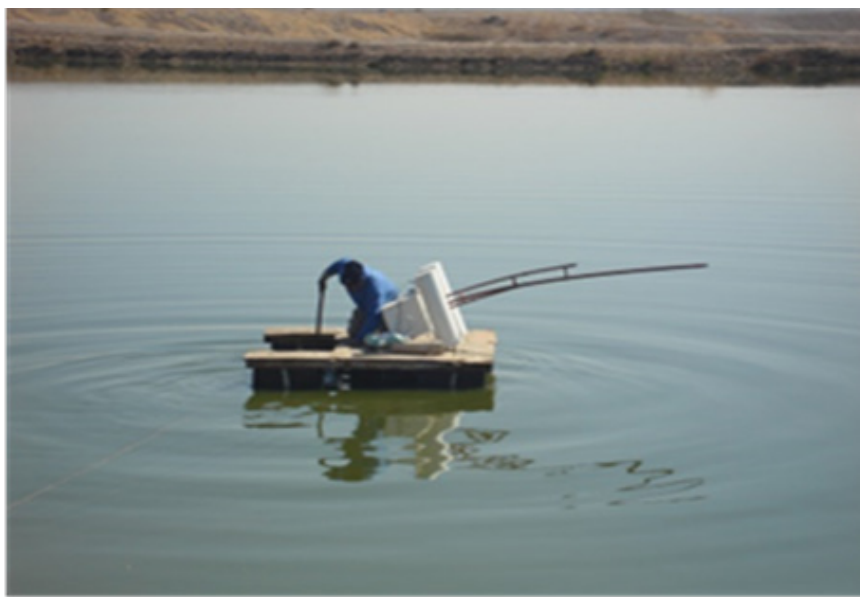

Figura 8: Extracción de datos del datalogger

- Este instrumental fue montado en una balsa de acero inoxidable y dentro de una caja de madera pintada para proteger el gabinete de la intemperie y la radiación solar. (Flores J. et al. , 2014)

- Una vez montados sobre la balsa, los sensores de temperatura miden este parámetro en tres profundidades distintas: 0,74 m (Superficial), 1,20 m (media) y 2,34 m (profunda). El último sensor no se utiliza por no presentar variación de temperatura respecto de la del aire.

\section{Correlación de temperatura.}

En la siguiente tabla se muestran los valores medidos de las temperaturas media del agua 
y del aire, también se muestra, la temperatura del agua estimada ( $\mathrm{T}^{\mathrm{o}}$ estimada) en función de la temperatura del aire mediante la correlación encontrada en este trabajo y mediante otras expresiones matemáticas reportada por la bibliografía que son utilizadas en la región. En el gráfico $\mathrm{N}^{\circ} 9$ se muestra el ajuste lineal y la expresión matemática con una correlación de $\mathrm{R} 2=0,9749$, que ajusta la relación entre la temperatura del aire y la temperatura del agua mensual en el presente estudio.

\begin{tabular}{|c|c|c|c|}
\hline MES & $\begin{array}{l}\text { T. líquido en el sensor } \\
\text { cercano a la superficie } \\
\text { (medida) }{ }^{\circ} \mathrm{C}\end{array}$ & $\mathrm{T}$. aire (dato) ${ }^{\circ} \mathrm{C}$ & $\begin{array}{c}\begin{array}{c}\text { Correlación en este } \\
\text { trabajo }\end{array} \\
\mathrm{Ta}=1,0322 * \mathrm{~T}^{\circ} \mathrm{ai}+0,469\end{array}$ \\
\hline ENERO & 27,43 & 27,30 & 28,65 \\
\hline FEBRERO & 26,20 & 23,43 & 24,65 \\
\hline MARZO & 24,92 & 23,41 & 24,63 \\
\hline ABRIL & 21,03 & 19,13 & 20,21 \\
\hline MAYO & 15,90 & 13,78 & 14,69 \\
\hline JUNIO & 11,60 & 10,55 & 11,36 \\
\hline JULIO & 9,54 & 9,25 & 10,02 \\
\hline AGOSTO & 12,25 & 13,02 & 13,91 \\
\hline SEPTIEMBRE & 15,30 & 14,78 & 15,72 \\
\hline OCTUBRE & 15,69 & 14,32 & 15,25 \\
\hline NOVIEMBRE & 21,03 & 19,76 & 20,87 \\
\hline DICIEMBRE & 23,88 & 23,57 & 24,80 \\
\hline
\end{tabular}

Tabla 2: Valores medidos de las temperaturas media del agua mas cercano a la superficie y del aire

En los Gráficos 1, 2, 3 y 4, se muestran las correlaciones encontradas entre los valores promedios diarios y mensuales de las temperaturas del líquido y del aire medidos a una profundidad superficial y una profundidad media en la laguna terciaria del sistema de tratamiento de efluentes de Campo Espejo durante el período Enero 2015- Diciembre 2015. 


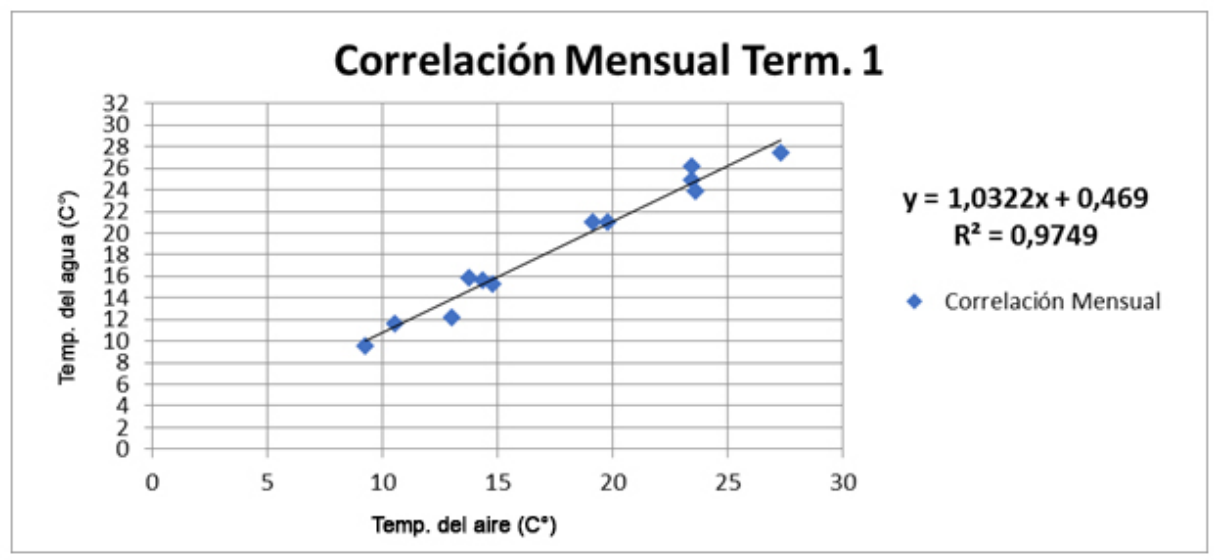

Gráfico N¹: Correlación entre el promedio mensual de las temperaturas del agua-aire. Termómetro ubicado en profundidad superficial.

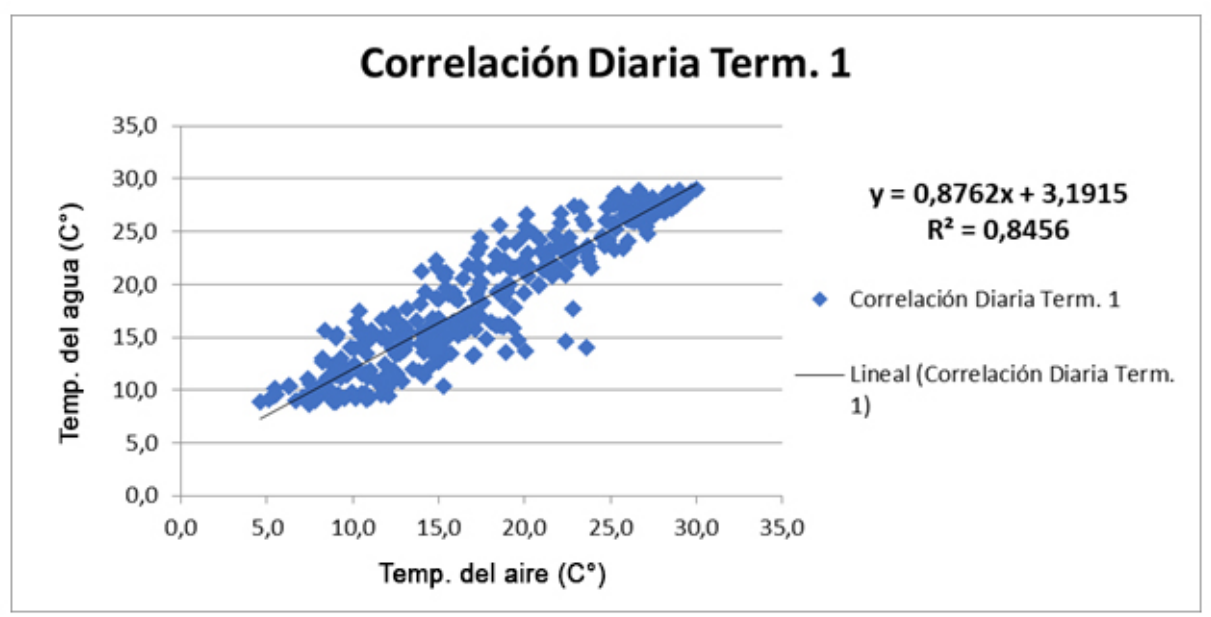

Gráfico N²: Correlación entre el promedio diario de las temperaturas del agua-aire. Termómetro ubicado en profundidad superficial. 


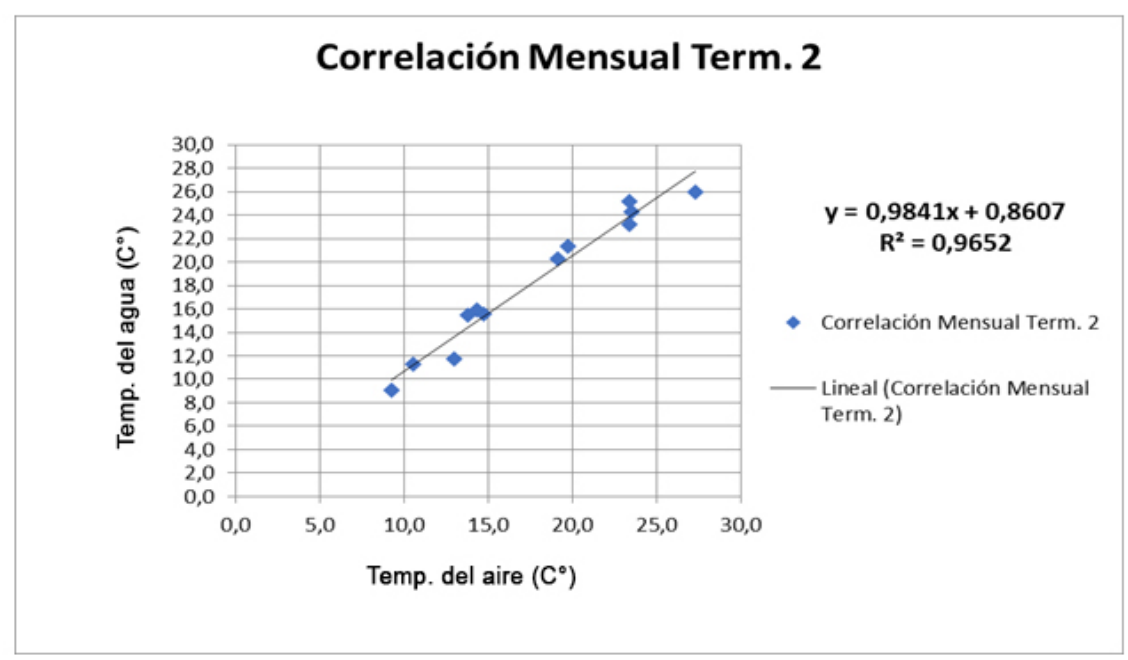

Gráfico N³: Correlación entre el promedio mensual de las temperaturas agua-aire. Termómetro ubicado en profundidad media.

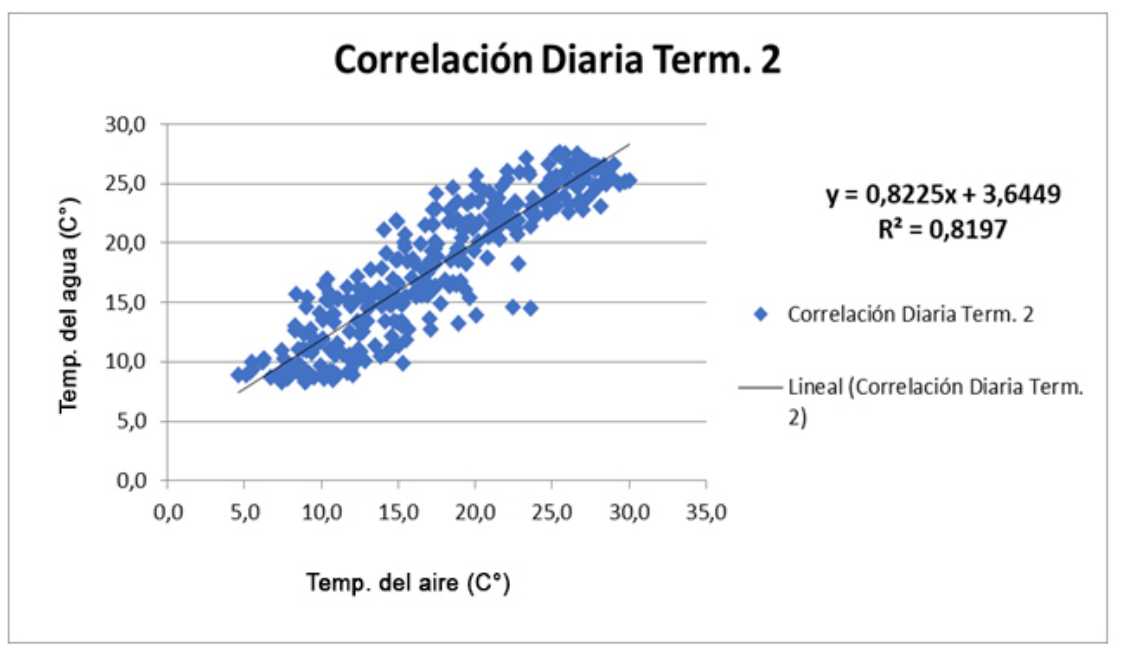

Gráfico N4: Correlación entre el promedio diario de las temperaturas agua-aire. Termómetro ubicado en profundidad media.

\section{Análisis de gráficos}

El coeficiente $\mathrm{R}^{2}$ determina la calidad del modelo para replicar los resultados, y la proporción de variación de los resultados que puede explicarse por el modelo. Es sin más, el cuadrado del coeficiente de regresión lineal denominado $\mathrm{R}$, por lo tanto, su valor mínimo es 0 y el valor óptimo es 1 .

El modelo que mejor ajusta los datos experimentales es Tagua $=0,469+1,0322$.Taire corresponde a las temperaturas promedio mensuales del sensor mas cercano a la superficie, con un coeficiente de determinación de $\mathrm{R}^{2}=0,9749$, lo que indica que el ajuste del modelo es muy bueno. 
También se determinó un modelo para las temperaturas promedio diarias, (para el cálculo de ellas se tomó los valores diarios de temperatura con un intervalo de 15 minutos y se los promedió) con un coeficiente de $\mathrm{R}^{2}=0,8456$, cuya ecuación de ajuste es Tagua $=3,1915+$ 0,8762.Taire.

\section{CONCLUSIONES GENERALES DE ESTA INVESTIGACIÓN}

- Se considera que las constantes determinadas y utilizadas en el modelo de predicción de calidad bacteriológica de efluentes de lagunas facultativas a base del submodelo de flujo disperso, comparado con las mediciones de campo y de laboratorio, de los abatimientos bacteriológicos para las diferentes temperaturas del líquido, son apropiadas para su uso en futuros proyectos de ingeniería de lagunas de estabilización de la región. Se observó una marcada dependencia de la constante de mortandad bacteriana neta $\mathrm{Kb}$ respecto de la temperatura del líquido de la laguna, prácticamente igual a la propuesta por Yañez en 1968.

- Referente a la certeza de las constantes cinéticas obtenidas en la investigación, las diferencias obtenidas entre los valores de concentración de bacterias en el efluente calculadas con el modelo analítico, calibrado con las constantes determinadas in situ, y los valores de concentración bacteriana del efluente efectivamente medidas en campo, varían del 1\% al 4\% diferencias que se consideran aceptables.

- Por otra parte, las importantes herramientas analíticas y tecnológicas sobre este tipo de tratamiento de efluentes, desarrolladas sobre todo a partir de los últimos años, no han sido diseminadas adecuadamente entre profesionales de la Ingeniería Sanitaria y Ambiental, según reportan los principales investigadores en la materia , por lo cual el estudio de las distintas variables de cálculo y su aplicación concreta , como se pretende con la presente investigación , puede contribuir, en cierta forma , a la divulgación regional de las mencionadas herramientas.

- El modelo de correlación de temperatura del agua y del aire obtenido ha sido aceptable, ya que se aproxima lo suficiente al modelo ideal R2=1,00. El mismo, permitirá predecir la temperatura del líquido durante el año y con ello, mediante el uso de distintas metodologías matemáticas, la eficiencia de remoción bacteriológica y orgánica del sistema de tratamiento de efluente de la ciudad de Mendoza, para compararlas con las condiciones de operación del sistema actual y para diseñar otras unidades en condiciones climáticas similares. (Saracho M. et al. , 2005)

- El modelo que mejor relaciona los datos experimentales es el que corresponde a las temperaturas promedio mensuales, con un coeficiente de determinación mayor al del modelo obtenido para las temperaturas promedio diarias. 


\section{REFERENCIAS}

Saracho, M.; Rodríguez, N.; Luque, V.; Rodríguez, C.; Iriarte, A. ; Plaza, G. (2005) "Estudio del comportamiento de lagunas de estabilización de efluentes: modelo de regresión temperatura aire-agua”, ASADES, Vol. 9. Disponible en: https://www.mendoza-conicet.gob. ar/asades/modulos/averma/trabajos/2005/2005-t001-a006.pdf

Poujol, A. (2018) “Tratamiento de aguas residuales mediante lagunas de estabilización”. Disponible en: https://es.slideshare.net/ArmandoEmilioPoujolC/tratamiento-de-aguasresiduales-mediante-lagunas-de-estabi

Yáñez, F. (1983) "Manuales de métodos experimentales: Evaluación de lagunas de estabilización”, CEPIS, Serie técnica 24. Disponible en: https://docplayer.es/75865814Inoi3vzillflvls3-30-svnr9v130-noi3vniva3.html y https://www.ircwash.org/sites/default/ files/341.1-82MA-3906.pdf

Flores , J.; Ghellinaza , E.; Lopez , M.; Finochiaro , O. ; Toum , E.; (2014) “Presentación AIDIS - $19^{\circ}$ Congreso Argentino de Saneamiento y Medio Ambiente del 21 al 23 de mayo Determinación de un modelo de correlación entre temperatura del aire y temperatura del agua en lagunas estabilización facultativas". 